\title{
Z dziejów biblioteki kanoników regularnych lateraneńskich w Mstowie: druki XVI wieku w BUW ${ }^{1}$
}

Biblioteka klasztoru kanoników regularnych lateraneńskich w Mstowie nie była dotychczas przedmiotem osobnych badań. Wymieniano ją jedynie omawiając koncentrację zbiorów bibliotecznych w okresie Księstwa Warszawskiego lub posupresyjną akcje Samuela Bogumiła Lindego². Tylko Kazimierz Latak, piszący dzieje Mstowa w związku z laskami słynącym obrazem Matki Bożej, wspomnial o bibliotece liczącej ponad trzy tysiące woluminów, w tym wiele rękopisów $\mathrm{i}$ inkunabułów ${ }^{3}$. Byl to więc księgozbiór niemały, zważywszy, że klasztor mstowski, choć jest jednym $z$ najstarszych na ziemiach polskich (jego początki sięgają XII w. ${ }^{4}$ ), to - jak również wykazywał ks. Łatak - „nie należal

\footnotetext{
${ }^{1}$ Niniejszy artykuł jest poszerzona wersją komunikatu wygłoszonego na konferencji ..Historyczne księgozbiory klasztorne”, zorganizowanej w 2006 r. przez Bibliotekę Śląską w Katowicach.

${ }^{2}$ Marian Lodyński, Materiaty do dziejów państwowej polityki bibliotecznej w Księstwie Warszawskim i Królestwie Polskim (1807-1831), Wroclaw 1958 i ks. Zdzislaw Wajzner, Los bibliotek klasztornych $w$ Gidlach,Mstowie i Wielgomtynach podekreciesupresyjnymarcybiskupa warszawskiego Franciszka Malczewskiego, .Częstochowskie Wiadomości Diecezjalne”, 43:1969, nr 3-6, s. 131-136. Ostatnio także wzmianka Iwony Pietrzkiewicz, Źródla do badań bibliotek kanoników regularnych na terenie Rzeczypospolitej, Ślq̨ska i $w$ Wielkim Księstwie Litewskim, w: Kultura ksiqziki ziem wschodniego i potudniowego pogranicza Polski (XVI-XX wiek). Paralele i różnice, red. nauk.: Jolanta Gwioździki Edward Różycki, Katowice 2004, s. 426-443, gdzie na s. 440 znajdujemy informację o zachowanym w AGAD katalogu mstowskim. Niestety nie udało się go tam odszukać. Mstowscy kanunicy otrzymali na przełomie XVI i XVII w. bibliotekę Jana Strzembosza, zob. więc E. Bylinowa, Renesansowy ksiegozbiór rodziny Strzemboszów, w: Ksieggozbiory szlacheckie XVI-XVII w.: kolekcje histonyczne, Warszawa 2004, s.17-87.

${ }^{3}$ K. Łatak CRL, Sanktuarium Matki Bożej Mstouskiej, Ełk 2000, s. 25 (niestety bez podania źródła).

${ }^{4}$ W 1 polowie XII w. Piotr Włostowic podarował Mstów opactwu NMP z góry Ślęży (ok. 1148 przeniesionemu na wrocławski Piasek). Ze względu na oddalenie od Wrocławia wkrótce powstała w Mstowie prepozytura z uposażeniem stanowiącym 11,2\% majątku opactwa (zob. Anna Pobóg-Lenartowicz, Uposażenie i dzialalność gospodarcza klasztoru kanoników regularnych NMP na Piasku we Wroctawiu do poczqtku XVI $w$., Opole 1994, oraz prace dotyczace architektury: Helena Hohensee-Ciszewska, Przypuszczenia o romańskich zatożeniach kościotów w Mstowie $i$ Ktobucku, w: „Biuletyn Historii Sztuki”, 27:1965, z. 2, s.160-162/4, Pawel Detloff, Kościót kanoników regularnych lateransskich w Mstowie, „Kwartalnik Architektury i Urbanistyki”, 43:1998, z. 4, s. 291-306). Pierwotnie kościól nosil wezwanie św. Augustyna, następnie - Wniebowzięcia NMP. Samodzielność i podniesienie do rangi kolegiaty otrzymali mstowscy kanonicy w 1441 r. Od 1781 r. przynależeli do kongregacji trzemeszneńskiej. Po drugim rozbiorze Polski znaleźli się w zaborze pruskim, a po likwidacji Księstwa Warszawskiego w zaborze rosyjskim. Do skasowanego w 1819 r. klasztoru kanonicy powrócili w roku 1990.
} 
egzemplarzy), zawartych w 428 woluminach $^{38}$, których mogło być w Mstowie więcej, gdyż spora część dzieł wielotomowych nie zachowała się w całości ${ }^{39}$ a niekompletne wydania zdarzają się te $\dot{z}$ w Spisie. Do naszych czasów dotrwało $\mathrm{z}$ nich 178 dziel w 211 tomach, z czego BUW posiada 187 woluminów. Spośród ksiązek zachowanych do dziś 79 egzemplarzy nie figuruje w Spisie... a co najmniej 44 z nich już wcześniej służyły profesorom i uczniom Liceum Warszawskiego.

$Z$ przeprowadzonej analizy chronologicznej wynika, że zwiększa się w omawianym zbiorze nie tylko ilość książek wydrukowanych w kolejnych dziesięcioleciach, ale wzrasta też ilość zachowanych egzemplarzy ${ }^{40}$. Oprócz inkunabułów (i czterech współoprawnych $z$ nimi dzieł $z$ lat 1501, 1505, 1507, 1521) druków sprzed 1536 r. doliczyliśmy się przynajmniej $77 . Z$ nich przetrwało do naszych czasów pięć $(6,5 \%)-z$ lat: 1529,1533 , dwa z $1534,1535^{41}$. Wydawnictw $z$ ostatniej ćwierci XVI stulecia bylo w Mstowie minimum 176 i z nich zachowało się 98 $(55,7 \%)$ dzieł. Przypuszczalnie to właśnie książi najstarsze, a więc uchodzące za najcenniejsze, padły ofiarą wspomnianej konfiskaty w 1832 r.

Książki gromadzone w Mstowie pochodziły $\mathrm{z}$ największych ośrodków drukarskich Europy: Kolonii, Wenecji, Bazylei i Antwerpi ${ }^{42}$. Nieco ponad 35\% (44\% przy uwzględnieniu Bazylei ${ }^{43}$ ) wydano w Niemczech. Juz znacznie mniej, po ok. 16\% pochodziło z Francji i Włoch. Taki rozkład geograficzny odpowiada (choć $z$ pewną nadreprezentacją ksiązek $z$ sąsiednich Niemiec) rozmiarom produkcji piśmienniczej i drukarskiej XVI stulecia ${ }^{44}$ i jest typowy dla innych polskich bibliotek $^{45}$. Druki krakowskie stanowią 10,5\% tytulów i 11,2 \% zachowanych egzemplarzy.

\footnotetext{
${ }^{38} \mathrm{~W}$ tym cztery dziela współoprawne $\mathrm{z}$ inkunabułami, więc nie wliczamy ich do sumy woluminów $z$ XVI w.

${ }^{39}$ Np. tylko po Strzemboszach moglo to być ok. 20 wol. więcej - Bylinowa, dz. cyt., s. 21 i 32.

${ }^{40} 1501-1510-21 \mathrm{dz}$. (w tym 3 wspóloprawne $z$ inkunabulami) -0 zachowanych; 1511-1520 - $27 \mathrm{dz}$. (1 wspóloprawne $\mathrm{z} X V \mathrm{w}$.) - 0 zachowanych; $1521-1536-33 \mathrm{dz}$. -5 zachowanych; $1537-1550-46 \mathrm{dz}$. -23 zachowane; 1551-1575 - $105 \mathrm{dz}$. -52 zachowane; 1576-1600-176 dz. - 98 zachowanych.

${ }^{41}$ Najciekawsze to: ERASMUS Desiderius Roterodamus, Epitome... in Elegantiarum libros Laurentii Vallae..., Lipsiae 1534 - BUW Sd.608.125 oraz s. HILDEGARDIS, Physica ..., Argentorati 1533 - BUW Sd.602.156; na tym egzemplarzu, znanym ze Spisu (2०-117), rozpoznajemy sygnatury Cesarskiej Akademii Nauk. Potwierdzony związek z Mstowem już w XVI w. ma jednak chyba tylko Novi Testamenti totius editio D. Hieronymo interprete, Coloniae 1529 - BUW 1225 . Wlaścicielem byl kanonik regularny lateraneński ks. Józef z Żórawia, prebendariusz mstowski w 1591 r.

${ }^{42}$ Oto najważniejsze: Kolonia - 65, Wenecja - 53, Kraków - 43, Bazylea - 36, Lyon - 35, Antwerpia -24, Strasburg - 19, Frankfurt n.M. - 18, Paryż - 14, Rzym, Lipsk, Wittenberga - po 10 pozycji.

${ }^{43}$ Bazylea należy do niemieckiego obszaru językowego i jej produkcje wydawniczą obejmuje Verzeichnis der im deutschen Sprachbereich erschienenen Drucke des 16 Jahrhunderts, Bd.1-22, Stuttgart 1983-1995.

${ }^{44}$ Por. Gedeon Borsa, Druki XVI wieku - glównym punktem wspótczesnych badań księgoznawczych, „Biuletyn Biblioteki Jagiellońskiej”, 46:1996, s.35: „druki z niemieckiego obszaru językowego... stanowią $32 \%$, druki włoskie - 28\% .. z z francuskiego obszaru językowego... ok. 20\% ogólnej ich liczby".

${ }^{45}$ Podobnie w Bibliotece Bożego Ciała w Krakowie: Kolonia, Wenecja, Bazylea, Antwerpia, Lyon - zob. Pietrzkiewicz, dz. cyt., s. 142, tab. 3.
} 
Przegląd zawartości merytorycznej księgozbioru mstowskiego i szczegółową analizę wspomnianego katalogu z 1704 r. zaprezentujemy w planowanej monografii. Możemy już jednak powiedzieć, że treść książek była dość typowa: dominowaly dzieła o tematyce religijno-kościelnej, teologiczno-filozoficznej i historycznej, zaś matematyczno-przyrodnicze i medyczne były nieliczne.

Na podstawie not proweniencyjnych stwierdzamy, że większość zachowanych egzemplarzy znalazła się w Mstowie już w XVI-XVII wieku ${ }^{46}$. Glównym źródłem pozyskiwania zbiorów były oczywiście dary ${ }^{47}$ : prepozytów (Baltazara Małuskiego, Andrzeja Strzembosza czy później Ignacego Kozierowskiego), poszczególnych kanoników (jak np. Adama Czarnysza ${ }^{48}$, Andrzeja Michałowicza ${ }^{49}$, Albina Łęczyńskiego ${ }^{50}$ ) oraz ich krewnych (np. kolekcja Jana Strzembosza, pojedyncze ksiązki innych Małuskich ${ }^{51}$ ). Zdarzają się też egzemplarze autorskie, np. Marcina Białobrzeskiego ${ }^{52}$.

${ }^{46}$ Blisko 40\% stanowią noty z XVI/XVII w.: Conventus Mstoviensis, Sum Conventus Mstoviensis, Ex libris Conventus Mstoviensis. Zapis Ex cathalogo librorum Conventus Mstoviensis (rzadziej Inscriptus cathalogo), duktem zbliżonym do pisma katalogu z 1704, widnieje na $28 \%$ egzemplarzy.

${ }^{47}$ Zob. Aldona Chlewicka, Dary w bibliotekach. Zarys problematyki badawczej, w: Bibliologia. Problemy badawcze nauk humanistycznych, praca zbiorowa pod red. D. Kuźminy, Warszawa 2007.

${ }^{48}$ Syn Walentego z łęczycy, student Akademii Krakowskiej 1560 (Adam Chmiel, Album studiosorum Universitatis Cracoviensis, Cracoviae 1896, t. 3, s. 35), bakalarz. Pozostawił w Mstowie dwa dziela w czterech woluminach: Catechismus ex decreto Concilii Tridentini, Coloniae 1570 - BUW Sd.608.2747 oraz TOPIARIUS Aegidius Dominicus, Conciones in Evangelia et Epistolas... IP. 1-3], Parisiis 1577-1578 - BUW Sd.608.5689 ${ }^{11,3\}}$. Na okładzinie katechizmu widnieją tłoczenia: ADAM CZARNISZ LANCITIENSIS ARTIUM BACAL[AUREUS] 1570. Ks. Ludwik Zaleski wspomina o jeszcze jednej oprawie $z$ tym nazwiskiem i takąż data - zob. Biblioteka seminarium duchownego w Lublinie i biblioteki klasztorne w diecezji lubelskiej i podlaskiej, Warszawa 1926, s.254-255 - ale bez autora czy tytulu. Na okładzinie dolnej wspomnianego wyżej kopiariusza mstowskiego znajdujemy tloczenia: FR[ATER] ADAMUS C (koniec linii, nisko:) LANCITIENSIS 1588. Odnoszą się one $z$ pewnością do Czarnysza. Nie możemy jeszcze stwierdzić, czy byl on redaktorem początkowej części kopiariusza, co zdaje się wynikać z tłoczenia na okładzinie górnej kodeksu: Sermones ex octernionibus in unum redacti - por. Kozerska i Stummer, dz. cyt., s. 50.

${ }^{49}$ W 1619 posiadał dzieło: CANISIUS Petrus s., Opus catechisticum, sive de Summa doctrinae Christianae... Ed. 3, Coloniae 1586 - BUW Sd.602.1461. Posługiwal się Biblia, Venetiis 1541, z kolekcji Jana Strzembosza - Bylinowa, dz. cyt., poz.14. Żyl jeszcze w I. 30-tych, bo jego wpisy widnieją na drukach zl. 1627-1631.

${ }^{50}$ Kronikarz konwentu mstowskiego, sekretarz kapituły, proboszcz w pobliskim Olsztynie; w młodości autor dysertacji Signacula septem theologica..., Varsaviae 1696, wygłoszonej w kolegium warszawskim jezuitów, gdzie był słuchaczem teologii i kanonów, podpisanej dwoma imionami: Albin Stanisław (zob. Stownik polskich teologów katolickich, pod red. ks. H. Wyczawskiego, Warszawa 1982, t. 2, s. 567). Na książkach podpisywał się jedynie imieniem Albin. Posiadał przynajmniej dwa druki z XVI w: LAGUS Conradus, Methodica iuris utriusque traditio..., Lugduni 1566- BUW Sd.608.4133; Speculum aulicarum... [Strassburg] 1600 - BUW Sd.618.184. Dotychczas zarejestrowano $\mathrm{z}$ jego wpisem 10 wol. $\mathrm{z}$ XVIl $\mathrm{w}$. w BUW i jeden w Bibliotece Narodowej: MALSKI Andrzej, Cursus theolosophiae Marianae..., Cracoviae 1643 - BN XVI.2.396.

${ }^{51}$ Np. po księdzu Michale Małuskim zostały w 1 polowie XVIII w.: DADRAEUS Ioannes, Loci communes similium et dissimilium... Ed. 3, Wirzeburgi - BUW Sd.608.3417 oraz SCHÖNBORNER Georg, Politicorum libri VII. Ed. 3, Lipsiae 1619 - BN XVII.1264.

${ }^{52}$ Wymieniona w przypisie 27 Sacrosancti sacrificii missae assertio... z superekslibrisem, jak uważamy, donacyjnym. Cystersi w Sulejowie również posiadali to dzieło $z$ superekslibrisem autora - por. BUW 958. 
Znamy niewiele książek należących do prepozyta Baltazara Małuskiego; tylko dwa dzieła w sześciu woluminach: Epitome sermonum dominicalium... Jana Ferusa (Wilda), popularnego franciszkańskiego kaznodziei i egzegety ${ }^{53}$ oraz monumentalne, pięciotomowe Opera św. Augustyna w kolejnej bazylejskiej edycji z 1569 r., z wytloczoną na okladzinie górnej datą: $1574^{54}$. Wszystkie tomy oznaczono jednak superekslibrisami $z$ herbem Jastrzębiec. Występują one w dwóch wariantach, skromniejszym na kazaniach i rozwiniętym, z dewizą „Virtus ardua petit" na pismach patrona zakonu ${ }^{55}$. Wprawdzie oba zastosowane stemple były wówczas popularne w Małopolsce, ale już samo ich użycie świadczy o przywiązywaniu wagi do posiadania ksiazzek i ich zewnętrznej postaci. Natomiast tytulatura tloczona na oprawach w formie skróconej: „B M P M" lub rozwiniętej: „BALTHAZAR MALUSKI CONVEN[TUS] MSTOVIENSIS PREPOSITUS" [!] może oznaczać, że był prepozytem dłużej, niż tylko w latach 1564$1568^{56}$.

Największy zespół proweniencyjny biblioteki kanoników w Mstowie stanowi dar podstarościego i sędziego grodzkiego radomskiego Jana Strzembosza (ok. 1545 - po III 1606), powiększony zakupami jego syna Andrzeja, tamtejszego wieloletniego prepozyta (1599-1640). Z kolekcji Strzemboszów zachowały się 83 dzieła w 126 woluminach, w tym 75 tytulów w 108 tomach wydrukowano w XVI stuleciu $^{57}$.

Przypuszczamy, że przed przekazaniem daru do biblioteki klasztornej dokonano selekcji tematycznej, stąd zdecydowanie przeważa w nim współczesna literatura filozoficzno-teologiczna i religijno-kościelna. W jej świetle Jan Strzembosz prezentuje się jako katolik otwarty na nowinki i polemiki religijne ${ }^{58}$. Posiadal np. edycję konfesji augsburgskiej, dzieła Iodoka Cocciusa, Franciszka Costera czy Fryderyka Staphylusa, $z$ polskich autorów np. Stanisława Ostrowskiego, Hieronima Powodowskiego, Adriana Radzimińskiego ${ }^{59}$. Wyraźnie interesował się jezuitami i ich twórczością. Nie wszystkie jego książki historyczno-polityczne (17\% zachowanych) trafily do Mstowa. Natomiast matematyczno-przyrodnicze imedyczne (łącznie 11\%) znacznie urozmaicily bibliotekęmstowskich kanoników, a nawet stanowily trzon działów bibliotecznych „Mathematici” i „Medici”.

${ }^{53}$ BUW Sd.608.259. W mstowskiej bibliotece znajdowało sie jeszcze jedno dzieło tego autora: In Ecclesiasten Salomonis annotationes..., Moguntiae, 1556 - BUW Sd.608.225. Natomiast w księgozbiorze kanoników w Kraśniku aż sześć różnych edycji sprzed 1563 - Zielińska, dz. cyt., s.166.

${ }^{54}$ BUW 576a (to samo wydanie posiadal późniejszy prymas Stanisław Karnkowski - 576b).

${ }^{55}$ Fotografie w: M. Cubrzyńska-Leonarczyk, Polskie superekslibrisy XVI-XVIII wieku w zbiorach Biblioteki Uniwersyteckiej w Warszawie. Centuria druga, Warszawa 2001, tabl. 26-27.

${ }^{56}$ Łatak, dz. cyt., s. 28. Zwlaszcza, że nie są znane nazwiska innych poprzedników ks. Mikołaja Leńka, kanonika gnieźnieńskiego w latach 1588-1599.

${ }^{57}$ Zob. Bylinowa, dz. cyt. Opublikowany katalog obejmuje 92 dzieła w 130 woluminach. W $2006 \mathrm{r}$. odnalazłam dodatkowo po jednej ksiażce ojca i syna. Większość swojej kolekcji podarował sędzia Jan do konwentu mstowskiego. Pojedyncze egzemplarze trafiły jeszcze (czasem przez inne osoby) do benedyktynów w Sieciechowie, bożogrobców w Miechowie, karmelitów bosych ss. Józefa i Michała w Krakowie.

${ }^{58}$ Bylinowa, dz. cyt., s. 22, 39 .

${ }^{59}$ Odpowiednio: BUW 566 i Bylinowa poz. 21, 25, 76, 59, 68, 69. 
Kolekcję sędziego Jana Strzembosza wyróżniają starannie dobrane oprawy i przede wszystkim złocone superekslibrisy $z$ herbem Jastrzębiec - sześć odmian w ośmiu wariantach.

Ks. Andrzej Strzembosz również oznaczał swój księgozbiór złoconymi superekslibrisami - znamy dwie odmiany w trzech wariantach. Dbał o solidne i trwale okładziny; $z$ jednym wyjątkiem wszystkie jego książki oprawiono w deski i obciągnięto jasną świńską skórą ze ślepymi tłoczeniami. Z księgozbioru prepozyta znamy 13 dzieł w 34 woluminach, wszystkie in folio. Są to wyłącznie książki religijne i teologiczne, a więc glównie dzieła Świętych Ojców (Bazylego Wielkiego, Hieronima, Grzegorza Wielkiego ${ }^{60}$ ) i Doktorów Kościoła (Bonawentury, Jana Damasceńskiego, Bernarda $z$ Clairvaux, Tomasza $z$ Akwinu ${ }^{61}$ ). Wszystkie w potrydenckich opracowaniach tak znakomitych patrologów jak Jakub de Billy, Jan Gallotius, Marianus Victorius Reatinus. Wymieniony zestaw autorów świadczy o świadomym uzupełnianiu zbiorów, wyposażaniu wspólnoty zakonnej w najważniejsze, fundamentalne teksty teologiczne, przede wszystkim dawne.

Zaangażowaniem w porządkowanie i wzbogacanie klasztornej biblioteki wyróżnił się jeden $z$ ostatnich mstowskich prepozytów - biskup Ignacy Augustyn Kozierowski h. Jelita (1708-1791) ${ }^{62}$. Informuje o tym odkryta w $1991 \mathrm{r}$. inskrypcja na ścianie dawnej biblioteki a obecnie kaplicy zakonnej: „....Bibliothecam hanc fornice nova reformavit, pictura et armariis adornavit, libros huc transtulit eosque variorum authorum auxit"63.

Superekslibris ${ }^{64}$ Kozierowskiego widnieje nie tylko na książkach i czasopismach wspólczesnych, np. na kilkunastu tomikach Summy św. Tomasza $z$ teologiczno-historycznym wykładem dominikanina Charlesa René Billuarta (Wirceburgi 1758) ${ }^{65}$, ale także na drukach wcześniejszych. ZXVII w. są to np. $A n$ nales Poloniae Wespazjana Kochowskiego z zamazaną proweniencją: „Ex Libris Fr[atris]..."66. Druków szesnastowiecznych jest dziesięć w dziewięciu woluminach. $Z$ nich już wcześniej do biblioteki klasztornej należały $z$ pewnością dwie książki $z$ podpisami Jana Strzembosza ${ }^{67}$. Dzieło poświęcone dzialalności Towa-

${ }^{60}$ Bylinowa, dz. cyt., poz. 9 (wydane w 1603 r.), 40 (1586), 36 (1588-1593).

${ }^{61}$ Bylinowa, dz. cyt., poz. 15 (wydawane w 1. 1588-1596), 43 (1577), 12 (1586), 79 (1592-1594).

62 Prepozyt od 1747, biskup adraneński 1763 i kanonik gnieźnieński 1767, sufragan gnieźnieński i administrator 1772-1777, kawaler orderu św. Stanisława 1786 - zob. Jan Korytkowski, Prataci i kanonicy katedry metropolitalnej gnieżnieńskiej, Gniezno 1883, t. 2, s. 322-327, oraz Piotr Nitecki, Biskupi Kościota w Polsce: stownik biograficzny, Warszawa 1992.

${ }^{63}$ Cyt. za Łatak, dz. cyt., s. 25, przypis 36.

${ }^{64}$ M. Cubrzyńska-L eonarczyk, Polskie superekslibrisy.... tabl. 99.

${ }^{65}$ Summa S. Thomae hodiernis academiarum moribus accomodata, sive cursus theologiae... Bd. 1-19, Suppl. - BUW 7.28.6.2.

${ }^{66}$ Cracoviae 1683 - BUW 4.27.1.30[1-2].

67 THOMAS de Aquino, s., Scriptum... in quatuor libros Sententiarum... Petri Lombardi, Venetiis 1586 z zapiska: Ex Catalogo librorum Conventus Mstoviensis oraz ostatni tom Theodori ZWINGERI, Theatrum humanae vitae..., Basileae 1586-1587, zawierajacy vol. 23-30, z zapiską: Sum Joannes Strzembosz (i niżj:) Conventui Mstovien/si] adhaereo - Bylinowa, dz. cyt., poz. 80 i 90. 
rzystwa Jezusowego na Dalekim Wschodzie ${ }^{68}$ (będące niegdyś własnością wybitnego drukarza a potem księdza Jana Januszowskiego) oraz dwa wspóloprawne zbiory homilii sławnego niemieckiego kaznodziei Fryderyka Nause ${ }^{69}$ mają na kartach tytułowych mstowskie noty własnościowe $z$ XVII wieku ${ }^{70}$. Prawdopodobnie mstowscy kanonicy już od dawna użytkowali części trzecią i czwartą Postylli Jakuba Wujka (wymieniane parokrotnie w katalogu z 1704 r.) oraz dwa egzemplarze Biblii w humanistycznych opracowaniach ${ }^{71}$ (oba zdefektowane). Właścicielem jednej $z$ tych Biblii był Mikołaj Rajski, notariusz publiczny, przed którym doszło w 1599 r. do ugody między klasztorem mstowskim i konwentem paulinów w Częstochowie ${ }^{72}$. Nie wiadomo, kiedy wpłynęły do zakonnego księgozbioru Confessiones św. Augustyna ${ }^{73}$, Postilla orthodoxa ${ }^{74}$ Marcina Białobrzeskiego i Messiasz Stanisława Karnkowskiego ${ }^{75}$ (nb. stanowiący część rozciętego później klocka). We wszystkich omówionych przypadkach pierwotne okładziny zapewne uległy zniszczeniu, a skoro były to wybitne dzieła znanych autorów (i w większości okazale, in folio), prepozyt polecil oprawić je na nowo i oznaczyć własnym herbem. Superekslibris biskupa Kozierowskiego nie jest tu więc znakiem właściciela, ale jedynie mecenasa, opiekuna księgozbioru. Już Joachim Lelewel twierdzil, że działalność biskupa Józefa Andrzeja Załuskiego spowodowała wzrost zainteresowania przełożonych klasztorówich bibliotekami ${ }^{76}$. Przypuszczalnie tak było i w Mstowie, gdzie właśnie w drugiej połowie XVIII w. uporządkowano księgozbiór. Opatrzono go sygnaturami, wypisanymi atramentem na verso okładzin górnych i grzbietach), zaś na kartach tytułowych pojawiła się zapiska: „Biblioth[ecae] Mstovien[si]s”.

Informacji o bibliotece mstowskiej poszukiwać będziemy także w aktach wizytacji biskupich oraz kronice klasztornej zapoczątkowanej przez wymienianego wyżej Albina Łęczyńskiego. Nie tracimy też nadziei na odnalezienie w bibliotekach seminaryjnych, zwłaszcza Warszawy i Włoclawka, kolejnych zachowanych ksiazzek mstowskiej proweniencji. Warto ich szukać dla pozyskania nowych tytułów do katalogu, ale także dalszych informacji o właścicielach i użytkownikach, o czasie wpływu do biblioteki itd. Jak już wspomniałam w grupie druków najstarszych owocna byłaby kwerenda w biblioteka rosyjskich, przede wszystkim w Petersburgu.

${ }^{68}$ Rerum a Societate Iesu in Oriente gestarum volumen primum... [et al.; ed. Ioannes Petrus Maffeius], Neapoli 1573.

${ }^{69}$ Współoprawne Evangelicae veritatis homiliarum centuriae quatuor... oraz Sermones adventuales... P. 2, Coloniae 1534 i 1535 - BUW Sd.602.2059-2060 adl.

${ }^{70}$ Odpowiednio: Conventus Mstoviensi Can [onicorum] Reg/ularium] Later/anensium/ i Sum ex libris Conventus Mstov/iensis/.

${ }^{71}$ Antverpiae 1540, Lipsiae 1544 - BUW 887.994.

${ }^{72}$ Kopiariusz mstowski, poz. 19 - Katalog Rękopisow Biblioteki Uniwersyteckiej w Warszawie, t. 1, nr 27a.

${ }^{73}$ Dilingae 1569 - BUW 588a.

${ }^{74}$ Kraków 1581 - BUW 957a.

${ }^{75}$ W Poznaniu 1597.

${ }^{76}$ Lelewel, dz. cyt., s.108-110. 